\title{
Mortality at Music Festivals: Academic and Grey Literature for Case Finding
}

\author{
Sheila A. Turris, NP, PhD; ${ }^{1,2,3}$ Adam Lund, MD, MEd, FRCPC ${ }^{1,4,5}$
}

1. Department of Emergency Medicine, University of British Columbia, Vancouver, British Columbia, Canada

2. School of Nursing, University of Victoria, Victoria, British Columbia, Canada

3. Vancouver Coastal Health Authority, Vancouver, British Columbia, Canada

4. School of Nursing, University of British Columbia, Vancouver, British Columbia, Canada

5. Emergency Department, Royal Columbian Hospital, New Westminster, British Columbia, Canada

\author{
Correspondence: \\ Sheila A. Turris, NP, PhD \\ Vancouver Coastal Health \\ 6th Floor, 132 West Esplanade \\ North Vancouver, British Columbia V7M \\ 1A2 Canada \\ E-mail: Sheila.Turris@ubc.ca
}

Conflicts of interest: none

Keywords: electronic dance music; Google Alerts; Internet surveillance; mass gatherings; music festivals

Abbreviations:

ED: emergency department

EDME: Electronic Dance Music Event

MCI: mass-casualty incident

Received: March 13, 2016

Revised: May 20, 2016

Accepted: June 2, 2016

Online publication: December 8, 2016

doi:10.1017/S1049023X16001205

\begin{abstract}
Objective: Deaths at music festivals are not infrequently reported in the media; however, the true mortality burden is difficult to determine as the deaths are not yet systematically documented in the academic literature.

Methods: This was a literature search for case examples using academic and gray literature sources, employing both retrospective and prospective searches of media sources from 1999-2014.

Results: The gray literature documents a total of 722 deaths, including traumatic (594/ $722 ; 82 \%)$ and non-traumatic $(128 / 722 ; 18 \%)$ causes. Fatalities were caused by trampling $(n=479)$, motor-vehicle-related $(n=39)$, structural collapses $(n=28)$, acts of terror $(\mathrm{n}=26)$, drowning $(\mathrm{n}=8)$, assaults $(\mathrm{n}=6)$, falls $(\mathrm{n}=5)$, hanging $(\mathrm{n}=2)$, and thermal injury $(n=2)$. Non-traumatic deaths included overdoses $(n=96 / 722 ; 13 \%)$, environmental causes $(n=8 / 722 ; 1 \%)$, natural causes $(n=10 / 722 ; 1 \%)$, and unknown/not reported $(n=14 / 722 ; 2 \%)$. The majority of non-trauma-related deaths were related to overdose $(75 \%)$.The academic literature documents trauma-related deaths $(\mathrm{n}=368)$ and overdose-related deaths $(n=12)$. One hundred percent of the trauma-related deaths reported in the academic literature also were reported in the gray literature $(n=368)$. Mortality rates cannot be reported as the total attendance at events is not known.

Conclusions: The methodology presented in this manuscript confirms that deaths occur not uncommonly at music festivals, and it represents a starting point in the documentation and surveillance of mortality.
\end{abstract}

Turris SA, Lund A. Mortality at music festivals: academic and grey literature for case finding. Prehosp Disaster Med. 2017;32(1):58-63.

\section{Introduction}

Music festivals in general, and Electronic Dance Music Events (EDMEs) in particular, are increasingly common and part of a 4.5 billion US dollar industry annually (Figure 1). ${ }^{1}$ There currently is no standardized definition for what constitutes a music festival. ${ }^{2}$ Music at EDMEs may have one or more of the following characteristics: (a) often, but not always, played by a DJ rather than being performed by musicians with instruments; (b) the music primarily is rhythmic (ie, repetitive) rather than melodic in nature; ${ }^{3}(\mathrm{c})$ vigorous dancing is common; ${ }^{4,5}$ and (d) recreational drug use often is part of the culture of the event. ${ }^{6,7}$ Mass-gathering events with these characteristics may be referred to as "EDMEs," "raves," "dance parties," "music festivals," and/or "house parties."

Compared with other types of events that involve young people gathering in large numbers, music festivals often are portrayed in the media to be higher risk and, in fact, may represent a public health issue. ${ }^{8,9}$ Documented non-traumatic risks of music festivals include: alcohol overuse,${ }^{10}$ drug use,${ }^{11-13}$ and drug overdoses related to the use of 3,4-methylenedioxy-N-methylamphetamine (MDMA) and related compounds, gamma-hydroxybutyric acid (GHB),${ }^{14}$ as well as other drugs such as LSD, mushrooms, ketamine, and stimulants. ${ }^{15}$ Trauma-related deaths from driving accidents ${ }^{11}$ and/or mass-casualty incidents (MCIs) also have been reported. ${ }^{16}$

Fifteen years ago, Weir argued that EDMEs were a significant source of mortality and morbidity and worthy of further attention by researchers and clinicians. ${ }^{9}$ Over the last 15 years, mainstream English media sources have reported deaths locally, nationally, and internationally in the context of music festival attendance. ${ }^{17-50}$ Health care professionals involved in the provision of on-site care at large music festivals experience first-hand the 


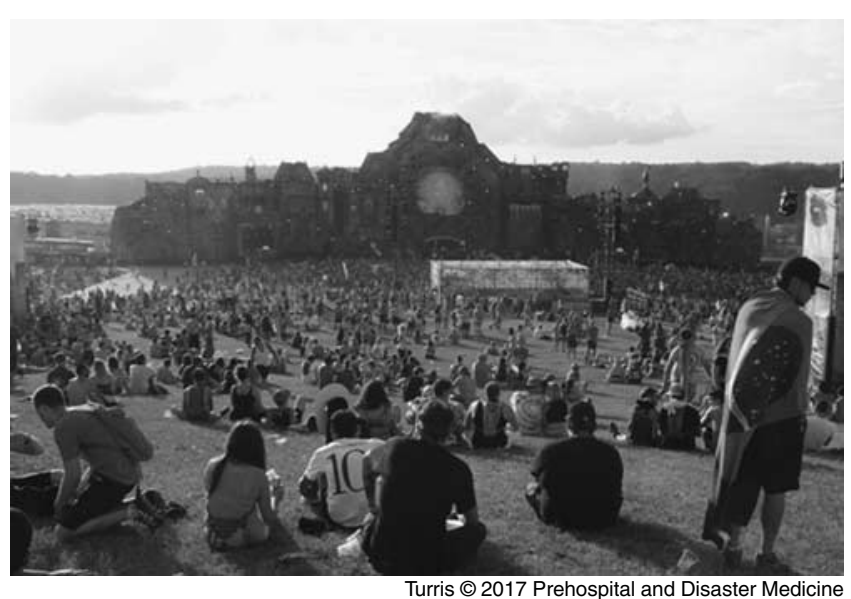

Figure 1. Music Festivals as Community Events.

Photo Credit: Dr. Adam Lund.

Note: No fatalities are attributed to the depicted event. The image proved an illustration of the crowd and the context of a music festival.

range of clinical presentations at these events, and researchers are just beginning to systematically document the illness/injury burden and case-mix associated with this category of event. ${ }^{10-14,51-53}$

In this manuscript, the authors present an analysis of fatalities associated with music festivals, drawn from both the academic and gray literature. In addition, the authors propose a systematic approach to using retrospective, iterative Internet searches and prospective Google (Google Inc.; Mountain View, California USA) Alerts in popular media as a source of data on mortality.

\section{Research Questions}

The questions used in this research were as follows:

1. How many and what types of fatalities were reported in the setting of music festivals from 1999 through 2014?

a. In the academic literature; and

b. In the popular media.

2. How might music festival-related fatalities be classified and categorized, inductively, for researchers, policy makers, medical directors, and event planners?

3. What are the sources and limitations of the evidence available for analysis?

\section{Methods}

\section{Case Finding}

A search strategy was created in consultation with a reference librarian (PB) and applied to the academic literature (Table 1). The authors also conducted a search of English language articles published in the mainstream media from 1999 through 2014, using academic and non-academic search terms. Retrospective case finding identified articles referencing death at eligible events in the last 15 years. Prospective Internet alerts were set up using Google Alerts through 2014. Search depth was a minimum of 10 pages deep.

Academic and media reports were used to locate new cases (eg, researchers [and reporters] sometimes cited previous, similar deaths). Names of victims (when publicly available) were recorded to prevent double counting. After a case was identified and recorded, a retrospective Internet search for the event name and

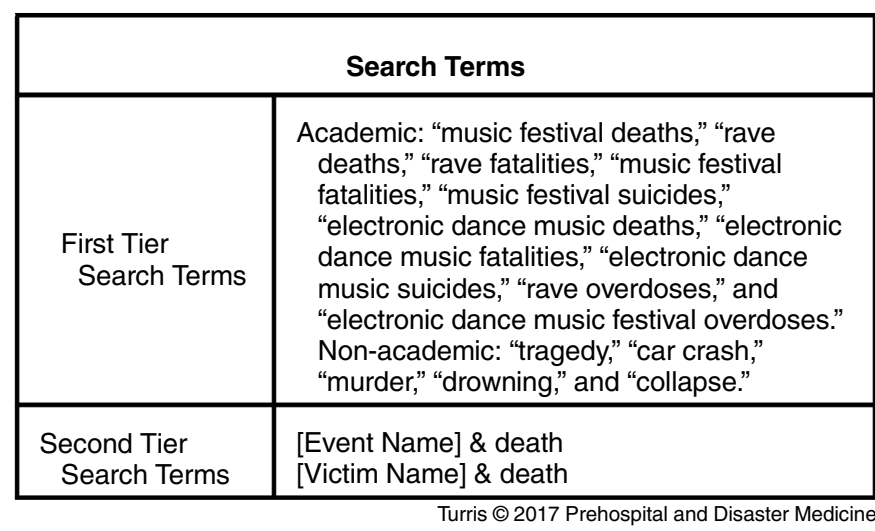

Table 1. Search Strategies for Primary and Secondary Sources

victim name was conducted, and a Google Alert was created to track prospective reports on the incident (eg, if a death was reported but no cause of death identified, information from later media reports, such as a delayed coroner's report, could be added to the spreadsheet). Additional information gleaned from these reports allowed the search strategy and database to grow and become more specific over time.

\section{Inclusion and Exclusion Criteria}

Reports were selected for review if: (1) they were published in the English language; (2) the death or deaths occurred from 1999 through 2014; (3) the report described a fatality related to attendance at a music festival; and (4) they included demographic information, such as the name and location (city/town and country) of the music festival, the month/year of the fatality, age of the deceased, and sex and/or name of the deceased.

Reports were excluded from review if the fatality: (1) was not clearly related to attendance at a music festival; (2) occurred in the setting of a permanent night club or dance venue; or (3) was only reported in private blogs or social media sites.

\section{Data Extraction and Analysis}

An Excel spreadsheet (Microsoft [Microsoft Corp.; Redmond, Washington USA] for Mac [Apple Inc.; Cupertino, California USA] 2011) was created for data extraction (Table 2). Data were reviewed and subsequently entered by research team members (ST, KL, AL). Classification and categories for fatalities were identified inductively as the data were collected and analyzed. Fatality data then were summarized.

\section{Categorizing Cases}

Cases were categorized according to proximal cause of death. For example, if an individual imbibed a recreational drug, became paranoid, and then ran into oncoming traffic, the case was categorized as a death resulting from trauma. Due to a general lack of detailed reporting on cause of death, overdose (ie, taking too much of a recreational drug or drugs) and poisoning (ie, death related to contaminated recreational drugs) were classified in the same category. If a death occurred off-site, but clearly was associated with attending a music festival, the case was included (eg, attendee ejected from event and then running into oncoming traffic).

\section{Ethics}

Ethics approval was applied for and waived by the University of British Columbia (Vancouver, British Columbia, Canada) 


\begin{tabular}{|l|}
\hline Date of Event \\
\hline Name of Music Festival \\
\hline Location of Event (Country/City) \\
\hline Number of Fatalities \\
\hline Name(s) of Deceased \\
\hline Date of Death \\
\hline Cause of Death \\
\hline Citation \\
\hline Notes Field \\
\hline
\end{tabular}

Table 2. Excel Data Extraction Fields

Research Ethics Board as data were collected from publicly available sources.

\section{Results}

\section{Gray Literature}

In the context of music festivals, there have been 722 deaths documented in popular media in the last 15 years, up to and including December of 2014 (Figure 2). Excluding the MCIs, for which the ages of the deceased are not recorded, ages of the deceased ranged from $14-82$ years ( mean $=23.8$ years).

Attributed causes initially were divided into trauma- (594/722; $82 \%)$ and non-trauma-related (128/722; 18\%) categories. Trauma-related deaths included nine MCIs (ie, 10 or more fatalities; $n=507)$. The majority of MCI deaths were the result of stampedes/trampling (eg, Emeneya Music Festival in 2014, Democratic Republic of Congo [ $\mathrm{n}=21$ ]; Love Parade in 2010, Germany $[\mathrm{n}=21]$; Mawaxine Festival in 2009, Morocco [ $\mathrm{n}=11$ ]; Cambodian Music Festival in 2008 [ $\mathrm{n}=347$ ]; South Korea in $2005[\mathrm{n}=11]$; and Sports Palace Festival in 1999, Belarus $[\mathrm{n}=54])$. One structural failure resulted in 16 fatalities (K-Pop Festival in South Korea, 2014). Two music festivals were the targets of acts of terror, including two bombings causing trauma-related deaths (Wings Festival in 2003, Moscow $[n=16]$; and Bangladesh New Year's Festival in $2001[n=10])$. Removing all nine MCIs from the analysis reduced the total number of all-cause fatalities substantially $(\mathrm{n}=215)$.

Non-traumatic deaths included overdoses ( $\mathrm{n}=96 / 722 ; 13 \%)$, environmental causes $(\mathrm{n}=8 / 722 ; 1 \%)$, natural causes $(\mathrm{n}=10$ / 722; $1 \%)$, and unknown/not reported $(\mathrm{n}=14 / 722 ; 2 \%)$. The majority of non-trauma-related deaths were related to overdose (96/128; 75\%; Table 3).

A total of 156 separate incidents resulting in deaths during music festivals were identified. Media reports of fatalities increased in frequency over the study period. For example, just over one-half of the incidents ( $\mathrm{n}=84 ; 55 \%)$ occurred between 2012-2014 and only six incidents (less than four percent) were documented for the first three years of the study period (1999-2001).

\section{Academic Literature}

The majority of deaths documented in the academic literature were captured in the gray literature $(\mathrm{n}=368)$. Conversely, only $51 \%(368 / 722)$ of the total number of music festival deaths identified were documented in the academic literature. The academic

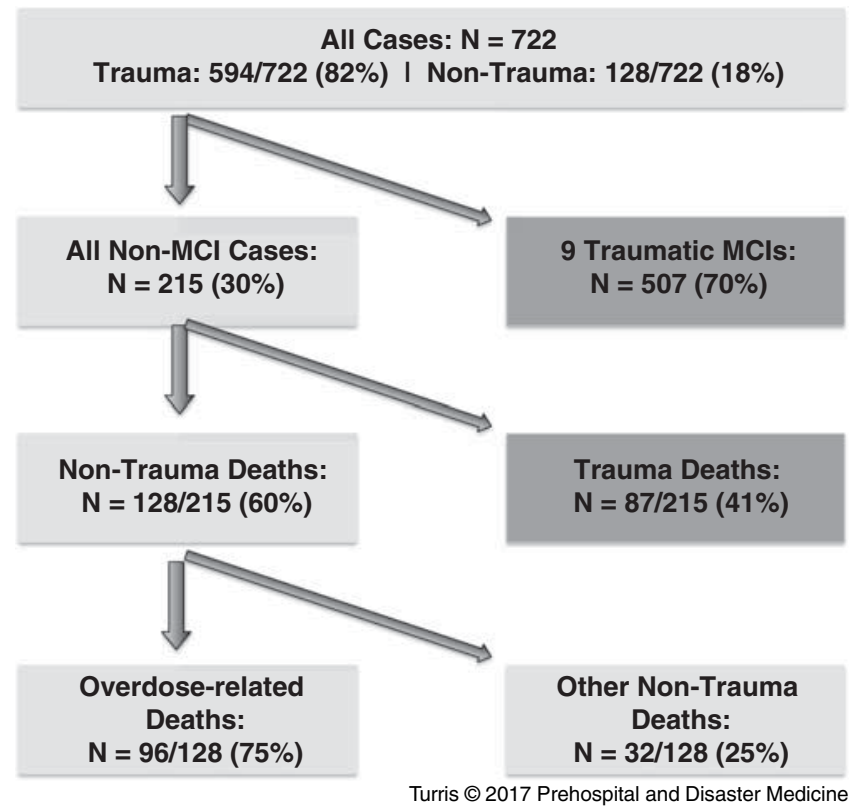

Figure 2. Media Reports of Music Festival Fatalities.

literature documented both trauma-related deaths $(\mathrm{n}=368)$ and overdose-related deaths $(n=12)$ at music festivals.

\section{Discussion \\ Epidemiology of Fatalities at Music Festivals}

Both academic and media reports confirm that the majority of deaths that occurred in the setting of music festivals were due to traumatic causes such as trampling, structural failures, and acts of terror. The majority of deaths occurred in the context of MCIs.

\section{Recommendation \#1: Plan for Traumatic Injuries and Mass-Casualty Incidents}

Given that $82 \%$ of deaths $(\mathrm{n}=594)$ at music festivals are due to trauma, many of which were MCIs, event pre-planning should include:

- disaster and emergency risk assessment and management planning;

- on-site ability for first response to trauma and orientation to responding to a MCI;

- pre-engagement with local emergency response agencies with responsibility to attend in the event of a disaster or MCI; and

- crowd management planning and crowd control procedures.

Recommendation \#2: Fund Research that may Decrease Alcohol and/ or Drug-Related Harms in the Context of Mass Gatherings

Non-traumatic fatalities related to music festival attendance were difficult to locate in the academic literature. The toxicology literature, for example, identified deaths related to overdose with recreational drugs in general, but typically provided no information about the setting in which an overdose or poisoning took place. ${ }^{54,55}$ Twelve overdose fatalities specifically related to music festival attendance were found in the academic literature (1996$2014)^{56-62}$ compared to 96 similar deaths in media reports. This finding confirms that there is currently a gap in the academic literature with regard to reporting of deaths associated with music festival attendance. 


\begin{tabular}{|c|c|c|c|c|c|c|c|}
\hline \multicolumn{8}{|c|}{ Total Deaths at Music Festivals: $\mathbf{N}=\mathbf{7 2 2}$} \\
\hline \multicolumn{4}{|c|}{ Traumatic Deaths: N = 594 (82\%) } & \multicolumn{4}{|c|}{ Non-Traumatic Deaths: N = $128(18 \%)$} \\
\hline & $\begin{array}{c}\# \\
\text { Deaths }\end{array}$ & $\begin{array}{c}\% \\
\text { Traumatic }\end{array}$ & $\begin{array}{c}\text { \% Overall } \\
\text { Deaths }\end{array}$ & & $\begin{array}{c}\# \\
\text { Deaths }\end{array}$ & $\begin{array}{l}\% \text { Non- } \\
\text { Traumatic }\end{array}$ & $\begin{array}{c}\text { \% Overall } \\
\text { Deaths }\end{array}$ \\
\hline Motor Vehicle Related & 39 & $7 \%$ & $5 \%$ & Natural Causes & 10 & $8 \%$ & $1 \%$ \\
\hline Structural & 28 & $5 \%$ & $4 \%$ & Environmental & 8 & $6 \%$ & $1 \%$ \\
\hline Acts of Terror & 26 & $4 \%$ & $4 \%$ & Unknown & 14 & $11 \%$ & $2 \%$ \\
\hline Drowning & 8 & $1 \%$ & $1 \%$ & & & & \\
\hline Totals & 594 & $100 \%$ & $82 \%$ & & 128 & $100 \%$ & $18 \%$ \\
\hline
\end{tabular}

Table 3. Total Deaths at Music Festivals Per Media Reports (1999-2014)

Given that $75 \%$ of non-traumatic fatalities at music festivals are associated with alcohol and/or drug-related factors, research is needed to understand the incidence, role, and risks of alcohol and drug-related harms and deaths at music festivals. Better characterization of attendee behavior, motivation, and culture may permit improved strategies for health promotion, injury/illness prevention, and harm reduction.

\section{Mortality and Morbidity}

Media sources seem much more likely to report on mortality than morbidity. Reports reviewed for this study rarely provided information regarding the number of patients seen and treated on site, and seldom provided information about the number of patients transferred by ambulance to an emergency department (ED). Further, increased workload at local EDs was not typically the subject of media reports. One exception was the media report for the Boonstock Festival, held in British Columbia in 2014, during which one death occurred and 80 people were transferred to hospital. ${ }^{63}$

In contrast, in the academic literature, three music festival case series and several case reports have been published, detailing the morbidity associated with such events. ${ }^{47,64-68}$ Existing academic reports support the hypothesis that music festivals have not only a mortality burden, but also a morbidity burden, which may be minimized by public health initiatives such as harm reduction strategies and by the integration of a medical team on site.

Recommendation \#3: Require Standardized, Centralized Reporting of Injuries, Illnesses, and Fatalities by All Health Stakeholders as Part of a Planned After-Action Debrief

Given the dearth of information in media reports about the number and impact of illnesses/injuries presenting to on-site medical teams and to local EDs and health infrastructure, make such deaths reportable to public health authorities. Such information might support evidence-based permitting, by-laws, licensing, and policies to support safe, enjoyable events. Quantifying the patient numbers and acuity will permit improved planning for on-site first aid and higher level of care emergency response, as well as planning for ambulance transports for off-site care.

\section{Limitations}

Gray Literature

Hsieh, Ngai, Burkie, and Hsu argued that non-traditional sources must be used in developing an understanding of the epidemiology related to illness and injury at mass gatheringss ${ }^{69}$ Grey literature is defined as work not published via traditional academic sources, and as such, not always widely disseminated or indexed. ${ }^{70,71}$ Increasingly, grey literature is becoming part of the mainstream flow of knowledge. ${ }^{72-75}$ Although use of grey literature may focus attention on a clinical issue well before it has been described clearly in the scientific literature, thereby shortening the average 17 year gap for translation into practice changes, ${ }^{76}$ there are both strengths and weaknesses to this approach.

A lack of indexing ${ }^{70,77}$ and no systematic retrieval system means that it is possible that many additional reports exist that were not located in this search, particularly going back in time. As well, the permanence of news articles on Internet-hosted sites is uncertain, so older cases may be lost to contemporary searches. The fact that the authors found relatively few online media reports in the early years of the study may be due to the fact that media links "go dark" after a certain period of time.

\section{Academic Literature}

The limitations of case finding in the academic literature were sobering. Because deaths from overdoses of recreational drugs are not uncommon, researchers seldom publish case studies on these deaths. Documentation of these deaths do not add to the scientific knowledge about reducing mortality and morbidity and therefore are unlikely to be accepted for publication. Comparing the number substance-use-related deaths reported in the gray literature with the number of deaths reported in the academic literature, the number of deaths related to attendance at music festivals is likely grossly under-reported in the academic literature. 


\section{Interpreting the Data}

Because data are not systematically collected and publicly reported post-event, the actual number of deaths related to music festival attendance is difficult to determine, but the number of incidents causing fatalities appears to be rising. This may be due to several factors. The number of music festivals being produced is increasing. It may be that the increasing number of deaths reported in this current study is an artifact of the absolute increase in the number of events rather than being attributable to events becoming "more unsafe." As well, media reports may have a short life cycle $^{90}$ and are influenced by what is considered newsworthy at a given point in time (ie, more drug-related deaths at music festivals may lead to more attention being focused on music festivals and so more cases brought to the attention of the public).

\section{Recommendation \#4: Develop a Prospective, Centralized Database to Track Music Festival Mortality and Morbidity and to Collect Event-Specific Data}

As such, prospective monitoring likely will yield a more complete picture of the mortality reported in the media.

\section{References}

1. Carmichael T. Electronic dance music (EDM) fan behavior differs greatly from that of other music fans. http://finance.yahoo.com/news/electronic-dance-music-edm-fan192420959.html. Accessed February 24, 2014.

2. Getz D. The nature and scope of festival studies. International J Event Management Res. 2010;5(1):1-25.

3. Krul J. Mass-gathering medicine at raves: incidents and substance-related emergencies. http://books.google.ca/books/about/Mass_Gathering_Medicine_at_Raves_ Inciden.html?id=nfqhoAEACAAJ\&redir_esc=y. Accessed November 18, 2014.

4. Office of National Drug Control Policy. Club drugs: facts and figures. www. whitehousedrugpolicy.gov. Accessed November 18, 2014.

5. Reider M. Some light from the heat: implications of rave parties for clinicians. CMAJ. 2000;162(13):1829-1830.

6. Grange JR, Corbett SW, Downs DM. The games: what can the sports medicine community learn from raves? Cur Sports Med Rep. 2014;13(3):155-162.

7. Castro RJ, Foy BD. Harm reduction: a promising approach for college health. $J A m$ College Health. 2010;51(2):89-92.

8. Madert K. The rise of electronic dance music: an in depth look at the current state of EDM. http://aladinrc.wrlc.org/handle/1961/15183. Accessed February 24, 2014.

9. Weir E. Raves: a review of the culture, the drugs, and the prevention of harm. CMAJ. 2000;162(13):1843-1848.

10. Johnson MB, Voas RS, Miller BA, Holder HD. Predicting drug use at electronic music dance events: self-reports and biological measurements. Eval Rev. 2009; 33(3):211-225.

11. Furr-Holden D, Voas RB, Kelley-Baker T, Miller B. Drug and alcohol-impaired driving among electronic music dance event attendees. Drug Alcohol Depend. 2006; 85(1):83-86

12. Johnson MB, Voas RB, Miller BA. Driving decisions when leaving electronic music dance events: driver, passenger, and group effects. Traffic Inj Prev. 2012; 13(5):577-584

13. Van Havere T, Vanderpalasschen W, Lammertyn J, Broekaert E, Bellis M. Drug use and nightlife: more than just dance music. Subst Abuse Treat Prev Policy. 2011;6: $1-18$.

14. Box SA, Prescott LF, Freestone S. Hyponatremia at a rave. Postgrad Med J. 1997;78 (885):53-54

15. Britt GC, McCance-Katz EF. A brief overview of the clinical pharmacology of "club drugs. Subst Use Misuse. 2005;40(9-10):1189-1201.

16. Soomaroo L, Murray V. Disasters at mass gatherings: lessons from history. PLOS Currents. 2012;4:1-12.

17. Romero D. 10 raver deaths in 5 years. LA Times. http://www.laweekly.com/informer/ 2012/06/20/10-raver-deaths-in-5-years-ecstasy-often-blamed?page=10. Accessed September 8, 2014.

18. Woodward J. Boonstock festival goer died on birthday trip. CTV News. http:// bc.ctvnews.ca/boonstock-festivalgoer-died-on-birthday-trip-1.1946025. Accessed September 24, 2014.

19. Fatima A. Drug-related deaths at Toronto's VELD Festival prompt homicide investigation. Globe \& Mail. http://www.theglobeandmail.com/news/toronto/siuinvestigating-death-of-concert-goer-handcuffed-by-police/article19906816/. Accessed September 1, 2014.

\section{Conclusion}

The results of this study begin to document the health impact of music festivals, confirming that there is a mortality burden associated with music festival attendance. The methodology presented here represents a necessary first step to quantifying the risks involved. Ongoing surveillance of music festival-related deaths will support the development of a data set upon which to test hypotheses and measure the effects of hazard and risk assessment, emergency pre-planning, health promotion, injury/illness prevention, and harm reduction efforts, as well as on-site emergency response interventions.

\section{Acknowledgements}

The authors wish to thank Ms. Kerrie Lewis for her superb work and meticulous organizational skills on this project; Dr. Brendan Munn for his ongoing collaborations with regard to music festival safety and emergency response; Ms. Pat Boileau, our reference librarian; and Dr. Alison Hutton for her comments on a draft version of this manuscript.

20. Perry T. USD student dies of drug overdose after on campus music festival. LA Times. http://www.latimes.com/local/lanow/la-me-ln-ucsd-student-drug-overdose-20140820story.html. Accessed September 10, 2014.

21. Humphries A, Hudes S. Who were the young people who died apparently from tainted drugs as music festivals? National Post. http://news.nationalpost.com/ 2014/08/06/who-were-the-young-people-who-died-apparently-from-tainted-drugsat-music-festivals/. Accessed September 9, 2014.

22. Bell D. Woman dies at Ottawa rave event; 2nd woman in coma. Ottawa Sun. http:// www.ottawasun.com/2014/07/04/woman-dies-at-ottawa-rave-event-2nd-woman-incoma. Accessed September 1, 2014.

23. Rettig J. 2 dead, 20 hospitalized after Mad Decent Party. http://www.stereogum. com/1696252/2-dead-20-hospitalized-after-mad-decent-block-party/news/. Accessed September 1, 2014.

24. Dearden L. Glastonbury 2014: reveler dies in hospital after taking ketamine. http:// www.independent.co.uk/arts-entertainment/music/news/glastonbury-festival-2014reveller-dies-in-hospital-after-taking-ketamine-9568197.html. Accessed September $15,2014$.

25. Gillfillan A. Death reported at Electric Forest music festival. Fox News. http://fox17online.com/2014/06/30/death-reported-at-electric-forest-music-festival/. Accessed September 10, 2014.

26. Young A. Second person dies at Electric Daisy Carnival 2014, marks seventh death since 2011. http://consequenceofsound.net/2014/06/second-person-dies-atelectronic-dance-carnival-2014-marks-seventh-death-since-2011/. Accessed September $15,2014$.

27. Tributes to Rio Andrew who died after Croydon Rave. BBC News. http://www. bbc.com/news/uk-england-london-27884915. Accessed September 1, 2014.

28. Yosh A. Two possible deaths at Ultra music festival this year; 2013 death attributed to bath salts. EDM News. http://www. Magneticmag.com/2014/04/two-possible-deathsat-ultra-music-festival-this-eyar-2013-death-attributed-to-bath-salts-overdose/. Accessed September 10, 2014.

29. Six dead from "meth" at Future music festival Asia, 2014. Sydney Herald. http://www. smh.com/au/entertainment/music/six-dead-from-meth-at-future-festival-asia-2014police-20140317-34wev.html. Accessed September 9, 2014.

30. Camber R. School boy Daniel Spargo-Mabbs, 16, dies after taking ecstasy at a rave. Mail Online. http;//www.dailymail.co.uk/news/article-2543272/SchoolboyDaniel-Spargo-Mabbs-16-dies-taking-ecstasy-rave.html. Accessed September 1, 2014.

31. Thomson I. Money, music, molly. Music Business Journal. http://www.thembj.org/ 2013/10/money-music-molly/. Accessed February 24, 2014.

32. Zattell J. Final day of New York electronic dance festival cancelled due to drug overdoses. CTV News. http://www.ctvnews.ca/entertainment/final-day-ofn-y-electronic-music-festival-cancelled-due-to-drug-overdoses-1.1435885. Accessed February 24, 2014.

33. Sherburne P. Tainted Ecstasy suspected. Spin News. http://www.spin.com/articles/ defqon1-death-sydney-suspected-overdose/. Accessed September 15, 2014.

34. 1 dead after drug overdoses at Washington concert. CBC News. http://www.cbc.ca/ news/worlds/1-dead-after-drug-overdoses-at-wash-concert-venue-1.1412755. Accessed February 14, 2014. 
35. Russell K. Police investigating whether a death is connected to drugs. WXYZ News. http://www.wxyz.com/nes/police-investigating-whether-a-death-is-connected-toa-rave-in-novi. Accessed September 9, 2014.

36. Martin N. 21-year-old dies after one drop of new synthetic drug. Times Picayune. http://www.nola.com/crime/index.ssf/2012/11/21-year-old_dies_after_one_dro.html. Accessed September 15, 2014.

37. Jordan B. Raver dies at BC music festival. CBC News. http://www.cbc.ca/news/ canada/ british-columbia/raver-dies-at-b-c-music-festival-1.1273834. Accessed February 24, 2014.

38. Grow D. Two deaths reported at the UK's V festival. Spin News. http://www.spin. com/ articles/two-deaths-reported-at-the-uks-v-festival/. Accessed September 15, 2014.

39. 2 dead among numerous drug, alcohol overdoses at Comcast Center rave concert. Sun Chronicle. http://www.thesunchronical.com/news/local_news/dead-amongnumerous-drug-alcohol-overdoses-at-comcast-center-rave/article_00aee02e-d500-543ab5c0-c626ba4f423b.html. Accessed September 2, 2014.

40. Deadly mix of drugs and rave. LA Times. http://graphics.latimes.com/towergraphiccoliseum-rave-deaths/. Accessed September 15, 2014.

41. Falconer B. Festival site death - inquest hearing this week. The Stroud. http://www. stroudlife.co.uk/Festival-site-death-inquest-hearing-week/story-28598847-detail/story. html. Accessed September 26, 2014.

42. Reilly J. Teenage, 19, dies and two of his friends are hospitalized after taking "legal high" Benzo Fury at music festival. Mail Online. http://www.dailymail.co.uk/news/ article2157524/RockNess02012-Alex-Heriot-dies-festival-taking-10-legal-high-BenzoFury.html. Accessed September 15, 2014.

43. Medical Examiner: Drugs at Kapolei rave led to woman's death. Star Advertiser. http://www.staradvertiser.com/news/breaking/147271455.html?id=147271455. Accessed September 15, 2014.

44. Cheston P. Clubber who died during 2-day rave killed by overdose. London Evening Standard. http://www.standard.co.uk/new/london/clubber-who-died-during-twodayrave-at-alexandra-palace-killed-by-overdose-not-rogue-ecstasy-7956584.html. Accessed September 15, 2014.

45. Ratliff B, Sisario B. Woman found dead at Bonnaroo. http://arsbeat.blogs.nytimes. com/2011/06/10/bonnarro-organizers-confirm-festival-attendees-death/?_php=true $\&$ _ type=blogs\&_r=0. Accessed September 15, 2014.

46. Dayglow incident sheds light on growing EMS problems of dance parties. JEMS http://m/jems.com/article/major-incidents/dayglow-incident-sheds-light-growing-ems. Accessed September 1, 2014.

47. Mascola L. Ecstasy overdoses at a New Year's Eve Rave. CDC Reports, MMWR. 2010;59(22):677-681.

48. Zanotti M. Big Day Out death inquest commences. Music Feed. http://musicfeeds. com/au/news/big-day-out-death-inquest-commences/. Accessed September 15, 2014.

49. Fun loving girl died of drug overdose at festival. Metro. http://metro.co.uk/2009/01/ 29/fun-loving-girl-died-of-drugs-overdose-at-festival-405945. Accessed September 15, 2014.

50. Stein J. Death at Bonnaroo music festival. LA Times. http://articles.latimes.com/ 2011/jun/14/news/la-heb-festival-20110614. Accessed September 15, 2014.

51. Ter Bogt TFM, Engels RCME. Partying hard: party style, motives for and effects of MDMA use at rave parties. Substance Use and Misuse. 2005;40(9-10):1479-1502.

52. Boles B. What's behind the music fest deaths? http://www.nowtoronto.com/news/ story.cfm?content=199323. Accessed September 15, 2014.

53. Dutch JM, Austin KB. Hospital in the field: prehospital management of GHB intoxication by medical assistance teams. Prehosp Disaster Med. 2012;25(5):463-467.

54. Gill JR, Hayes JA, de Souza IS, et al. Ecstasy (MDMA) related deaths in New York City: a case series and review of the literature. J Forensic Sci. 2002;47:121-126.

55. Milroy CM. "Ecstasy" associated deaths: what is a fatal concentration? Analysis of a case series. Forensic Sci Med Pathol. 2011;7(3):248-252.
56. Armenian P, Mamantov TM, Tsutaoka BT, et al. Multiple MDMA (ecstasy) overdoses at a rave event: a case series. J Intensive Care Med. 2013;28(4):252-258.

57. Bledsoe B, Songer P, Buchanan K, et al. Burning man 2011: mass-gathering medical care in an austere environment. Prehosp Emerg Care. 2012;16(4):469-476.

58. Duflou J, Mark A. Aortic dissection after ingestion of "Ecstasy" (MDMA). Am J Forensic Med Pathol. 2000;21(3):261-263.

59. Garcia-Repetto R, Moreno E, Soriano T, et al. Tissue concentrations of MDMA and its metabolite MDA in three fatal cases of overdose. Forensic Sci Int. 2003;135(2): 110-114.

60. Karlovsek MZ, Alibegovic A, Balazic J. Our experiences with fatal ecstasy abuse (two case reports). Forensic Science International. 2005;147:S77-S80.

61. Walterscheid JP, Phillips GT, Lopez AE, Gonsoulin ML, Chen HH, Sanchez LA. Pathological findings in 2 cases of fatal 25I-NBOMe toxicity. Am J Forensic Med Pathol. 2014;35(1):20-25.

62. Ridpath A, Driver CR, Nolan ML, et al. Illnesses and deaths among persons attending an electronic dance-music festival - New York City, 2013. MMRW. 2014; 63(50):1195-1198.

63. Chan C. Penticton's Boonstock festival ends with one dead, 80 sent to hospital. The Province. http://www.theprovince.com/Penticton+Boonstock+Festival+ends+with+ dead+sent+hospital/10089307/story.html\#_federated=1. Accessed November 6, 2014.

64. Krul J, Sanou B, Swart EL, et al. Medical care at mass gatherings: emergency medical services as large-scale rave events. Prehosp Disaster Med. 2012;27(1):71-74.

65. Hutton A, Ranse J, Verdonk N, et al. Understanding the characteristics of patient presentations of young people at outdoor music festivals. Prehosp Disaster Med. 2014;29(2):160-166.

66. Turris SA, Lund A. Mass-gathering medicine: risks and patient presentations at a 2-day electronic dance music event. Prehosp Disaster Med. 2015;30(3):271-278.

67. Molloy MS, Brady F, Maleady K. Impact of a single large mass gathering music event, from a series of such events, on a receiving hospital's emergency department (ED). Prehosp Disaster Med. 2013;28(1):S186.

68. Stagelund S, Jans O, Nielsen K, et al. Medical care and organization at the 2012 Roskilde music festival: a prospective observational study. Acta Anaesthesiologica Scandinavica. 2014;58(9):1086-1092.

69. Hsieh YH, Ngai KM, Burkle FM, et al. Epidemiological characteristics of human stampedes. Dis Med Public Health Prep. 2009;3(4):217-223.

70. University of British Columbia Library. Finding the hard to finds: searching for grey literature. http://www.slideshare.net/giustinid/finding-the-hard-to-finds-searchingfor-grey-gray-literature-2010. Accessed August 10, 2014.

71. University of British Columbia. Grey literature for health sciences. http://guides. library.ubc.ca/greylitforhealth. Accessed August 10, 2014.

72. Pisa Declaration on Policy Development for Grey Literature Resources Statement of Intent, April 7, 2014. http://eventi.isti.cnr.it/attachments/category/32/16_Pisa\% 20Declaration\%20(Draft,\%207\%20April\%202014).pdf. Accessed August 10, 2014.

73. Canadian Agency for Drugs and Technologies in Health. A practical tool for searching the evidence. http://www.cadth.ca/en/resources/finding-evidence-is/grey-matters. Accessed August 10, 2014.

74. GreyNet International. Grey Guide: a guide to good practice and resources in grey literature. http://www.greynet.org/greyguiderepository.html. Accessed August 10, 2014.

75. New York Academy of Medicine. http://www.nyam.org/library/. Accessed August 10, 2013.

76. Morris ZS, Wooding S, Grant J. The answer is 17 years, what is the question: understanding time lags in translational research. J Royal Soc Med. 2011;104(12): 510-520.

77. Keeling JW, Turner AM, Allen EE, et al. Development and evaluation of prototype search engine to meet public health information needs. AMLA Annual Symp Proceedings. 2011;2011:693-700. 